\title{
Nowhere to swim to: climate change and conservation of the relict Dades trout Salmo multipunctata in the High Atlas Mountains, Morocco
}

\author{
Miguel Clavero, Javier Calzada, Javier Esquivias, Ana Veríssimo \\ Virgilio Hermoso, A bieljebbar Qninba and Miguel Delibes
}

\begin{abstract}
Montane biota is vulnerable to climate change, especially in the case of relict species in environmentally extreme areas. The Dades trout Salmo multipunctata is a relict species from the Draa basin, on the southern slopes of the High Atlas Mountains, Morocco. Apart from its genetic and morphological singularity almost nothing is known about this species. We surveyed the whole potential distribution range of the Dades trout and found that only two isolated populations exist (in the Dades and M'Goun catchments), occupying an extremely small range, $<22$ $\mathrm{km}$ of stream reaches in a narrow altitudinal range (c. 2,150-2,375 m). The species was found more frequently and more abundantly at intermediate elevations within its range, and somatic condition increased with altitude. Climatically suitable areas for the Dades trout will be confined to mountain summits without permanent water bodies by 2070. The Dades trout is a Critically Endangered species in need of active management for its persistence. We propose actions for the long-term conservation of the species, including catchment-scale erosion control, riverbed restoration, local-scale measures to mitigate global warming, and an ex situ breeding programme.
\end{abstract}

Keywords Climate change, extreme environments, freshwater fish, Morocco, mountain biodiversity, Salmo multipunctata, threatened species

Supplementary material for this article is available at https:// doi.org/10.1017/Soo30605316001551

Miguel Clavero (Corresponding author) and Miguel Delibes Estación Biológica de Doñana, Consejo Superior de Investigaciones Científicas (EBD-CSIC), Américo Vespucio s.n., 41092 Seville, Spain

E-mail miguelclavero@ebd.csic.es

Javier Calzada Departamento de Ciencias Integradas, Universidad de Huelva, Huelva, Spain

JAVIER Esquivias Ecotono, Seville, Spain

Ana Veríssimo Research Centre in Biodiversity and Genetic Resources (CIBIOInBIO), Vairão, Portugal, and Virginia Institute of Marine Science, Gloucester Point, USA

Virgilio Hermoso Forest Sciences Centre of Catalonia, InForest Joint Research Unit, Solsona, Spain

AbDelJebbar Qninba Université Mohammed V-Agdal, Institut Scientifique, Rabat, Morocco

Received 18 August 2016. Revision requested 27 September 2016.

Accepted 10 November 2016. First published online 6 April 2017.

\section{Introduction}

ountain areas support an important component of biological diversity and often contain unique species assemblages (Körner \& Spehn, 2002) that are threatened by climate change (Nogués-Bravo et al., 2007). The ranges of such species are expected to shift upwards, tracking suitable climatic conditions (Pauli et al., 2012). However, such movements are limited by the decreasing amount of available habitat towards mountain summits. Thus, species occupying narrow altitudinal ranges at high elevations are particularly vulnerable to climate change (La Sorte \& Jetz, 2010).

The High Atlas mountain range in Morocco is a biodiversity hotspot that marks the southernmost distribution limit of several taxa with Palearctic affinities. The Saharan area of northern Africa has historically alternated between wet and dry periods (Drake et al., 2011), and as a result of this dynamism the biota of the region has elements of both Palearctic and Afrotropical origin. In the current arid period many of the Palearctic species in the region are confined to the wetter and cooler mountain areas (Brito et al., 2011a). These populations are doubly vulnerable, being confined to high mountains and occupying peripheral and environmentally extreme areas within the species' ranges. The brown trout Salmo trutta is an example of a Palearctic species with relict populations at high elevations within the High Atlas Mountains.

The brown trout is a cold-dwelling, widely distributed freshwater fish, whose vast area of distribution has been shaped by complex processes of range contractions and expansions associated with Pleistocene glaciations, giving rise to various genetic lineages (Bernatchez, 2001). The brown trout also exhibits significant variability in life history traits, including anadromous and stream- and lake-dwelling resident populations, which may differ in many ecological and morphological features. As a result of this complexity the taxonomy of the brown trout is still an unresolved matter (Pustovrh et al., 2014). Some authors consider the brown trout to be a single, complex species (Jonsson \& Jonsson, 2011), whereas others regard it as a species complex that contains many taxa (Kottelat \& Freyhof, 2007).

The southernmost populations of the brown trout, lato sensu, occur in the mountain systems of Morocco. An analysis of the genetic structure of Moroccan trout populations found that all but one fitted within the so-called Atlantic 
lineage (Snoj et al., 2011), which is the most common in European rivers draining to the Atlantic (e.g. Cortey et al., 2009). The exception was the population in the Draa River basin, on the southern slopes of the High Atlas Mountain range. These trout were found to belong to a previously unknown and ancient lineage, which was named the Dades lineage (after the Dades River; Snoj et al., 2011). The Dades trout Salmo multipunctata (Plate 1) was described as a new species by Doadrio et al. (2015), based on its genetic singularity, long isolation and morphological diagnostic features.

Notwithstanding the recent insights into the evolutionary history and taxonomic status of the Dades trout, almost nothing is known about its ecology and conservation status. All the information to date (Snoj et al., 2011; Doadrio et al., 2015) comes from a few individuals captured at two localities. Here we provide a full account of the distribution range of the Dades trout and analyse the environmental factors that may be limiting the species. We also evaluate the plausible role of climate change in its extinction risk, by modelling the trout's current and future distributions. Our ultimate aim is to produce useful information to guide the conservation of the Dades trout. We assessed its conservation status following the Red List guidelines (IUCN, 2012), and propose specific measures aimed at maximizing the chances for the long-term persistence of this unique trout.

\section{Study area}

The Draa is the longest river system in Morocco (c. 1,10o km; Fig. 1). The Dades and M'Goun rivers are the main headwaters of the Draa, and the only permanent rivers within the Draa system (Schulz \& Judex, 2008). These rivers drain a high mountain area with low human population density and restricted and sparse agricultural uses (although livestock is omnipresent). Vegetation includes high-altitude spiny shrub formations and sparse Juniperus woodsteppes, although bare terrain is common. Rivers are fast-flowing, with conductivities of $300-1,300 \mu \mathrm{S} \mathrm{cm}^{-1}$, and occasionally have woody riparian vegetation dominated by willows Salix sp.

\section{Methods}

\section{Fish sampling and data}

We surveyed 34 sites within an a priori defined potential range of the Dades trout. Based on a previous study (Clavero et al., 2015), this potential range included stream stretches in the Draa basin at $\geq 1,900 \mathrm{~m}$ altitude. Potential sampling sites were selected within this potential range by examining aerial photographs from Google Earth (Google Inc., Mountain View, USA), to avoid as much as possible

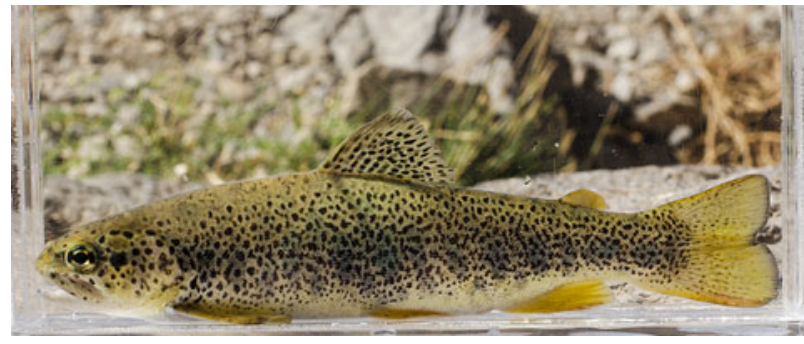

Plate 1 A Dades trout Salmo multipunctata, $211 \mathrm{~mm}$ in length, from the Imigmar stream, M'Goun River basin (Figs 1 \& 3c). (C) J. Esquivias.

sampling river stretches that were temporally dry. As a result of this selection process we identified 21 areas above $1,900 \mathrm{~m}$ with apparently permanent waters, covering c. $168 \mathrm{~km}$ of stream reaches (Supplementary Table $\mathrm{S} 1$ ).

Surveys were conducted during 6-20 August 2014. Most of the sites (27 of 34 ) were reached by foot, aided by mules to carry materials. The final dataset included three additional sites (i.e. 37 sites in all) that had been surveyed using the same methodology in March 2013 (Clavero et al., 2015). We sampled fish populations using a portable electrofishing device (model ELT6o II HI, Hans Grassl GmbH, Schönau am Königssee, Germany). At each site circa $100 \mathrm{~m}$ of stream (mean $95.6 \mathrm{~m}$; range $45-205 \mathrm{~m}$ ) was sampled, using a single pass without blocking, and direct pulse current (50-75 pulses per second). All captured Dades trout were measured for total length, to the nearest $\mathrm{mm}$. A sample of individuals were lightly anaesthetized with eugenol and weighed, to the nearest $0.1 \mathrm{~g}$. All fish were returned to the water, after ensuring recovery from anaesthesia if it had been applied.

The relative abundance of Dades trout at surveyed sites was quantified in terms of catch per unit effort (no. of individuals per $\mathrm{m}$ ), which was logarithmically $\left(\log _{10}(X+1)\right)$ transformed prior to analyses. We calculated the somatic condition of individuals using the scaled mass index (Maceda-Veiga et al., 2014; see Supplementary Material 1 for details of the calculation).

\section{Habitat, and trout-habitat relationships}

Twelve habitat variables were summarized by means of a principal component (PC) analysis, which provided two main gradients of variation in habitat features. Size-PC1 was related to the size (i.e. volume) of stream habitats, and Vegetation-PC2 reflected the variability in riparian vegetation cover. We retained elevation as a separate explanatory variable because of its presumed relevance for a highmountain organism such as the Dades trout. For a full account of the habitat characterization procedures used, see Supplementary Material 2 and Supplementary Table S2. 


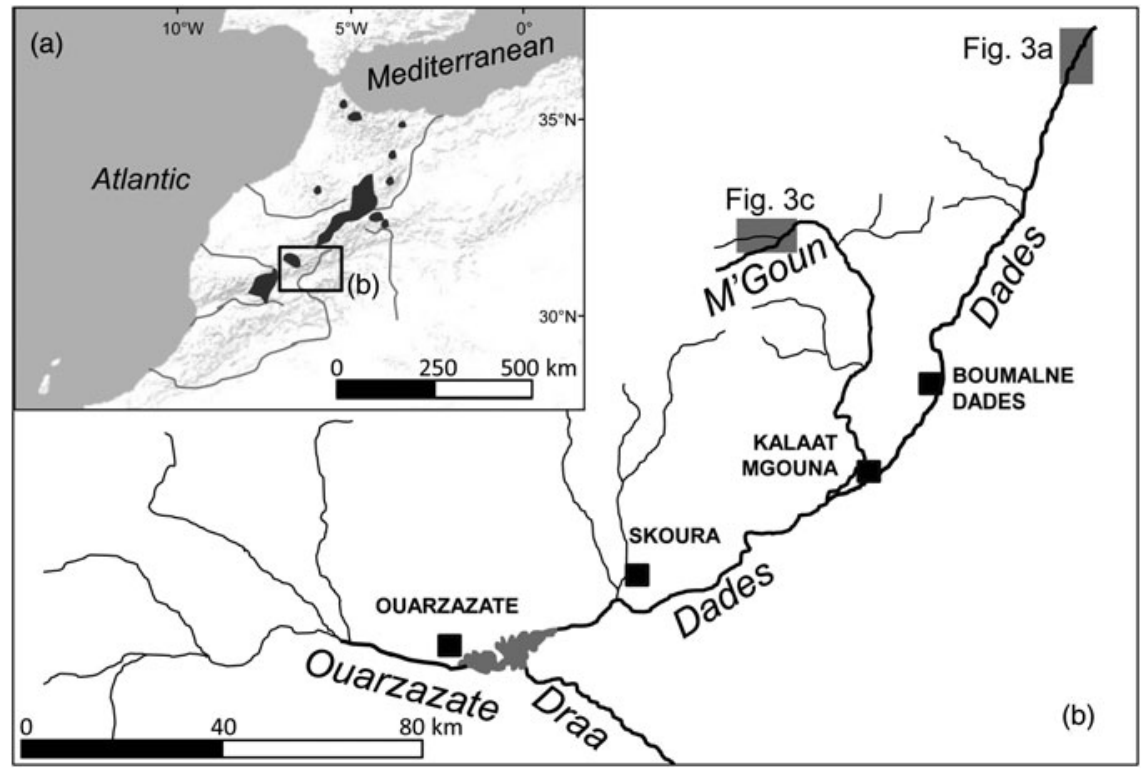

FIG. 1 (a) Shaded areas indicate the distribution of Salmo species in Morocco, based on Azeroual (2003). (b) The location of the Dades and M'Goun Rivers within the upper Draa drainage, showing the main water courses (labelled in italics) and urban centres (black squares). The shaded rectangles indicate the locations of Fig. 3a,c.
We modelled the occurrence, relative abundance (catch per unit effort), mean total length $(\mathrm{mm})$ and mean somatic condition (scaled mass index) of the Dades trout per sampling site, using elevation, squared-elevation (to allow for unimodal relationships), Size-PC1 and Vegetation-PC2 as predictors, by means of generalized linear models. Trout presence/absence was modelled using a binomial distribution of errors and logit link function, and catch per unit effort ( $\log _{10}$ transformed), mean size, and scaled mass index values were analysed using normal distribution of errors and identity link functions. For the analysis of catch per unit effort we considered only those sites where the Dades trout was present. Model selection was based on the Akaike information criterion (AIC). We ran all possible models combining the four predictor variables, with the restriction that squared-elevation was included only together with elevation. The model exhibiting the lowest AIC value was chosen as being the most likely, except in the case of equally informative (i.e. $\triangle \mathrm{AIC}<2$ ) nested models (i.e. models built by adding variables to a simpler one), of which we selected the simplest one.

\section{Current and forecast distribution}

We modelled the presence/absence of the Dades trout further using subcatchments as spatial units of analysis. We derived 1,996 subcatchments in the Draa basin upstream of the Dades-M'Goun confluence from a $90 \mathrm{~m}$ digital elevation model, using ARC Hydro in ArcGIS 10.1 (ESRI, Redlands, USA). Subcatchments had a mean area of $1.52 \pm$ SD 1.22 $\mathrm{km}^{2}$. The suitability of subcatchments for the Dades trout was estimated in terms of mean temperature, annual precipitation (both at $1 \mathrm{~km}$ resolution), mean slope, and drainage area, using a generalized boosted model algorithm
(D'Amen et al., 2013). Climatic variables were sourced from WorldClim (Hijmans et al., 2014), and topographic variables were derived from the digital elevation models using ArcGIS 10.1. The predictive performance of the generalized boosted model was evaluated based on the area under the receiver operating characteristic curve (AUC) by splitting data in calibration $(80 \%)$ and validation $(20 \%)$ subsets 10 times.

We projected the generalized boosted model suitability estimates to 2070, based on the future bioclimatic scenarios presented in the Fifth Assessment Report of the Intergovernmental Panel on Climate Change (sourced from WorldClim; Hijmans et al., 2014). To explore the effect of various representative concentration pathway (RCP) scenarios we projected habitat suitability for optimistic ( $\mathrm{RCP} 26)$ and pessimistic scenarios (RCP85) for the same general circulation model (Max Planck Institute Earth System Model at base resolution).

\section{Assessment of conservation status}

We used all the information gathered to develop a formal assessment of the global conservation status of the Dades trout, based on the Red List criteria (IUCN, 2012).

\section{Results}

\section{Range and habitat}

We found Dades trout in 16 of the 37 sampled sites, and captured 362 individuals. We found the trout only above $2,145 \mathrm{~m}$ and it was not found to coexist with other fish species. The entire distribution range of the Dades trout encompasses at 
most $22 \mathrm{~km}$ of stream channel in two isolated reaches, across an elevational range of c. $200 \mathrm{~m}$ (Fig. 2).

The species' range in the Dades basin is restricted to the N'Ougouni stream, the source of the Dades River (Fig. 3a). The species is absent downstream of the N'OugouniN'Ougni confluence as well as in other watercourses within the catchment (e.g. Oussikis-Idikel). The trout occurs from the N'Ougouni source (at 2,375 m altitude) to 2,190 $\mathrm{m}$, at which point the water, often the whole circulating flow, starts to be diverted for agricultural uses (Fig. $3 \mathrm{~b}$ ). The trout can be found downstream of this point when there is surplus water flow (down to 2,145 m), but only rarely and in very low numbers. The whole stream network occupied by the Dades trout in the Dades subcatchment is c. $12 \mathrm{~km}$.

In the M'Goun basin the Dades trout is concentrated in two right-margin spring-fed streams with permanent water flow: Aflafal and Imigmar (Fig. 3c). The maximum abundance of the trout within the catchment is found in the Aflafal stream, a short $(1.2 \mathrm{~km})$, spring-fed stream that has a high water flow until its junction with the M'Goun, at $2,288 \mathrm{~m}$ altitude. Imigmar stream has a much smaller flow, and the trout is over an order of magnitude less abundant there than in the Aflafal stream. The permanent water sector of the Imigmar stream is c. $2 \mathrm{~km}$ long and joins the M'Goun at 2,192 $\mathrm{m}$ altitude. The trout are rare along the main channel of the M'Goun. Near its source (at 2,655 m altitude) the M'Goun receives large amounts of fine sediments from several left-margin tributaries (Fig. $3 \mathrm{~d}$ ), and consequently its main channel has turbid waters and highly embedded substrates, producing an unsuitable habitat for trout. Furthermore, the upper M'Goun is fragmented by at least two waterfalls (Fig. 3c). Thus, the presence of trout in the M'Goun seems to depend on individuals colonizing from the population strongholds in right-margin tributaries. The whole stream network occupied by the Dades trout in the M'Goun subcatchment is c. $10 \mathrm{~km}$.

The analyses of the presence/absence and relative abundance data in relation to stream habitats produced similar results (Table 1). The Dades trout occurred more frequently at intermediate elevations within the sampled altitudinal range and was also more abundant at intermediate elevations within the occupied altitudinal range (Fig. 2). In both cases there was also a positive linear influence of the Size-PC1 gradient (Table 1), which suggests that trout populations are limited by the size of available aquatic habitats.

Captured trout were 53-244 mm in length (Supplementary Fig. S1). Mean sizes were smaller at sites with higher abundance (Pearson's $r=-0.57 ; \mathrm{P}=0.03 ; \mathrm{n}=14$ ), because of the higher proportion of juvenile individuals at more densely populated sites. Mean trout size reached a minimum at intermediate values of the species' altitudinal range, as individuals tended to be larger at both the upstream and downstream limits of the species' range
(Table 1; Supplementary Fig. S2), where catch per unit effort tended to be lower (Fig. 2). In contrast, somatic condition increased linearly along the elevation gradient occupied by the trout (Table 1; Supplementary Fig. S2), apparently indicating environmental limitations on the development of healthy trout populations near the downstream limit of the species' range.

\section{Current distribution and future forecasts}

The generalized boosted model had a high predictive performance (AUC $=0.96$ ), providing maximum suitability estimates in areas where the trout was present (Supplementary Fig. $\mathrm{S}_{3}$ ) and within the altitudinal range in which the species had been detected (Fig. 4). Projected suitability values were lower for 2070, under both the optimistic and the pessimistic bioclimatic scenarios. More suitable habitat is expected to shift to higher elevations in response to warming and changes in precipitation but it is unlikely the Dades trout will able to track this upward shift, given the scarcity of permanent waters and the presence of insurmountable waterfalls (Fig. 4). Everything else being equal, the only areas with relatively high suitability for the species by 2070 that currently have permanent waters will be limited to the M'Goun system.

\section{Assessment of conservation status}

If IUCN guidelines regarding geographical range metrics (criterion B) are strictly observed, the Dades trout would be categorized as Endangered. However, extent of occurrence (EOO) and area of occupancy (AOO) may significantly underestimate the extinction risk of freshwater species (e.g. Simaika \& Samways, 2010). Thus, we calculated the trout's EOO or AOO using approaches that took into account the discontinuity of its range, the hierarchical organization of river basins in subcatchment units and/or the area of suitable habitat within the EOO. A reassessment of the conservation status of the Dades trout using this approach resulted in its categorization as Critically Endangered. The full assessment and discussion of the limitations of IUCN geographical range metrics are provided in Supplementary Material 3.

\section{Discussion}

\section{The relevance of conserving the Dades trout}

Peripheral populations of widely distributed species (or species complexes) may be critical from a conservation perspective given their disproportionate importance for the maintenance of phylogenetic diversity and evolutionary potential (Lesica \& Allendorf, 1995). This seems to be the case 

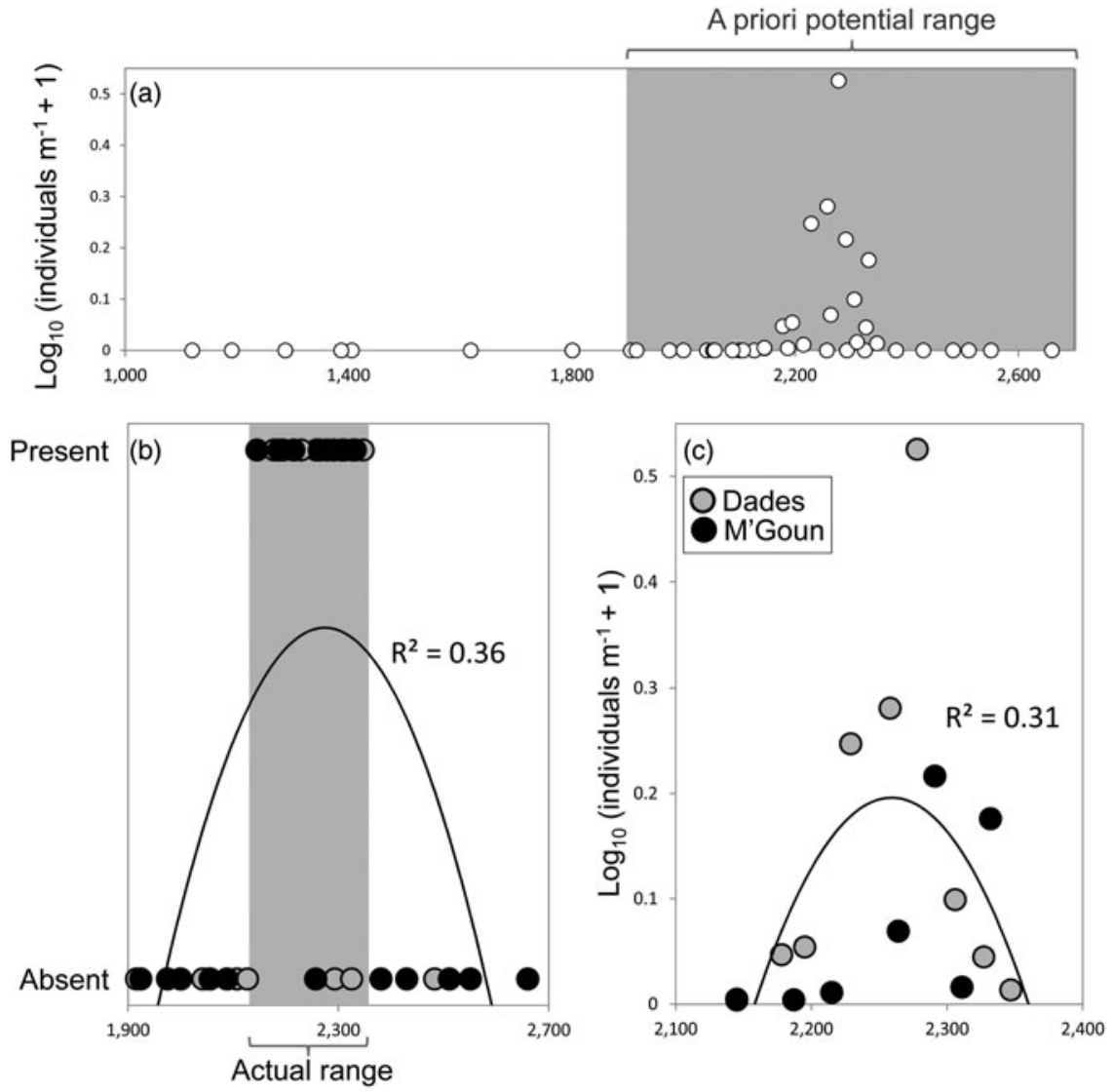

Elevation (m)
FIG. 2 (a) Relative abundance of the Dades trout Salmo multipunctata in relation to elevation, showing the potential elevation range of the species (grey rectangle) used a priori to select sampling sites. (b) Presence/absence of the Dades trout in relation to elevation within the potential elevation range defined in (a), showing the species' actual elevation range (grey rectangle). (c) Relative abundance of the Dades trout in relation to elevation, using data only from sites where the species is present. Fitted functions in (b) and (c) are second-order polynomials.
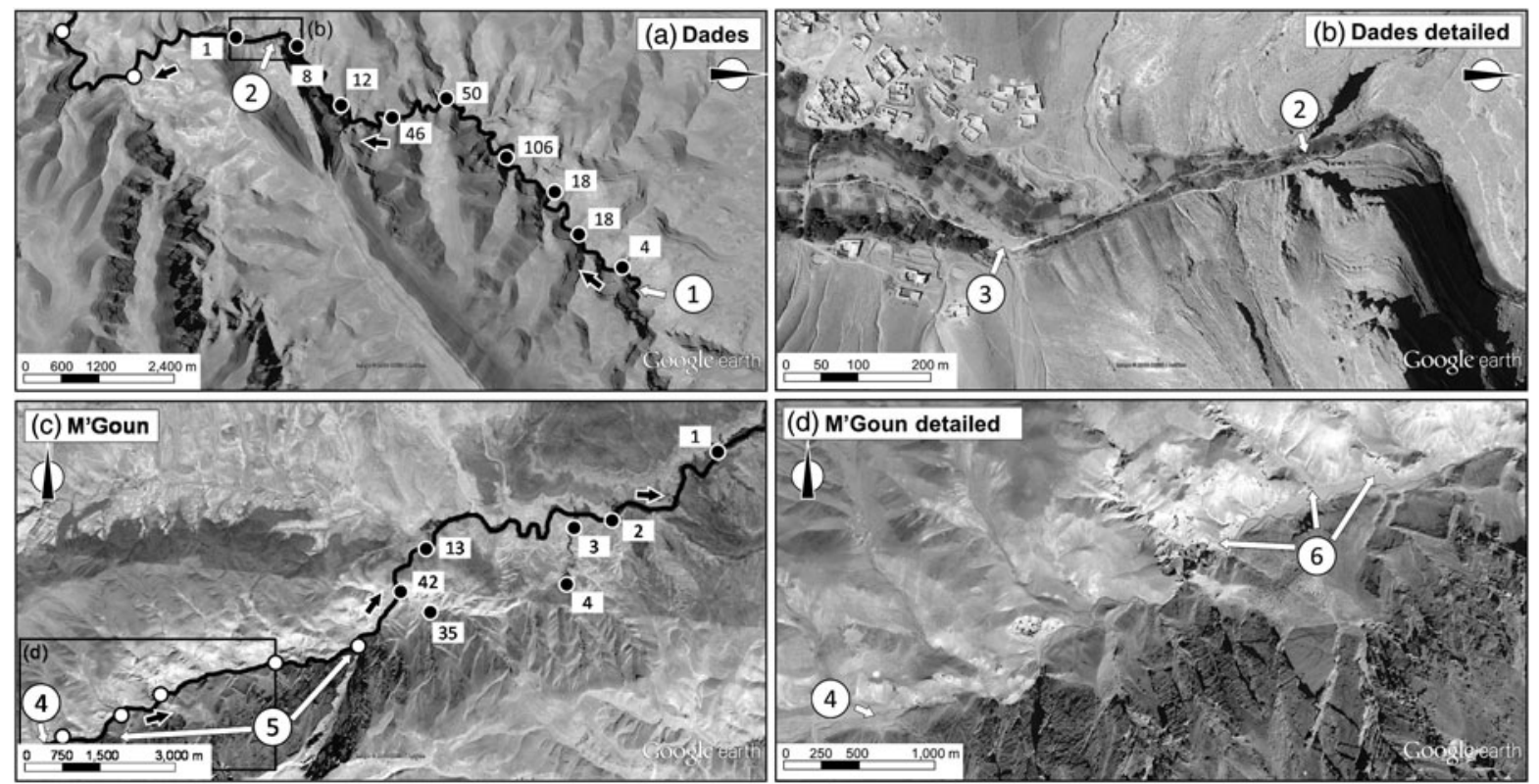

FIG. 3 General and detailed views of the range of the Dades trout in the Dades (a, b) and M'Goun (c, d) catchments. The main water courses and the direction of the flow (black arrows) are indicated in (a) and (c); filled circles indicate sampling sites where the trout was present (with numbers of captured individuals indicated); unfilled circles indicate sites where the trout was not detected. 1 , source of the N'Ougouni stream; 2, the water diversion structure; 3, dry river bed; 4, source of the M'Goun; 5, two insurmountable waterfalls in the upper M'Goun; 6, high embeddedness levels downstream. Data for background maps: Google, CNES/Astrium. 
TABLE 1 Results of the generalized linear models analysing the variation in occurrence, relative abundance, mean size and mean somatic condition of the Dades trout Salmo multipunctata across sampled sites in the High Atlas Mountains, Morocco (Fig. 1), with the direction (positive or negative) of the relationships between the dependent variables and the predictors included in the most parsimonious model, selected by means of the Akaike information criterion. The goodness of fit of selected models is estimated as the \% change in deviance as compared with the null model (i.e. that fitted without predictor variables).

\begin{tabular}{|c|c|c|c|c|}
\hline & $\begin{array}{l}\text { Presence/ } \\
\text { absence } \\
(\mathrm{N}=37)\end{array}$ & $\begin{array}{l}\text { Relative } \\
\text { abundance } \\
(\mathrm{N}=16)\end{array}$ & $\begin{array}{l}\text { Mean } \\
\text { size } \\
(\mathrm{N}=14)\end{array}$ & $\begin{array}{l}\text { Somatic } \\
\text { condition } \\
(\mathrm{N}=12)\end{array}$ \\
\hline Elevation & + & + & - & + \\
\hline Elevation $^{2 \star}$ & - & - & + & $\begin{array}{l}\text { Not } \\
\text { included }\end{array}$ \\
\hline Size-PC1 & + & + & $\begin{array}{l}\text { Not in- } \\
\text { cluded }\end{array}$ & $\begin{array}{l}\text { Not } \\
\text { included }\end{array}$ \\
\hline $\begin{array}{l}\text { Vegetation- } \\
\text { PC2 }\end{array}$ & $\begin{array}{l}\text { Not } \\
\text { included }\end{array}$ & $\begin{array}{l}\text { Not } \\
\text { included }\end{array}$ & $\begin{array}{l}\text { Not in- } \\
\text { cluded }\end{array}$ & $\begin{array}{l}\text { Not } \\
\text { included }\end{array}$ \\
\hline$\%$ deviance & 70.2 & 45.2 & 79.3 & 44.4 \\
\hline
\end{tabular}

${ }^{\star}$ The quadratic elevation term (Elevation ${ }^{2}$ ) was used to allow for unimodal responses.

for the Dades trout, which is genetically unique among African trout (Doadrio et al., 2015) and within the brown trout complex (Snoj et al., 2011). Snoj et al. (2011) suggested that the ancestors of the Dades trout would have colonized the Draa basin 1.5-1 million years ago, remaining in isolation thereafter. The low latitude position of the Draa estuary $\left(28.7^{\circ} \mathrm{N}\right.$, within the range of the subtropical Canary Islands) would have precluded later colonization waves, and contact with neighbouring trout populations does not seem to have occurred in spite of the widespread river captures recorded across the High Atlas (Babault et al., 2012). Future genetic studies, ideally integrating insights from different genetic markers and with a wide spatial coverage, should clarify the phylogenetic relationships of the Dades trout and the controversial taxonomy of the brown trout complex.

The lack of agreement on the taxonomy of the brown trout complex in general and that of the northern African trout in particular generates mixed perceptions of their extinction risk. According to the IUCN Red List (IUCN, 2016) there are 27 species in the brown trout complex, and the umbrella species (Salmo trutta) is not present in northern Africa. The Red List includes three African trout species, which are either lake-dwelling (the extinct $S$. pallaryi from Aguelmane Sidi Ali, in the Middle Atlas, and S. akairos from Lake Ifni, in the High Atlas) or range-restricted species of uncertain validity (S. macrostigma from coastal mountains in Algeria). Formal Red List assessments are still missing for the Dades trout (provided here) and for S. viridis from Lake Isly in the High Atlas (Doadrio et al., 2015). But most

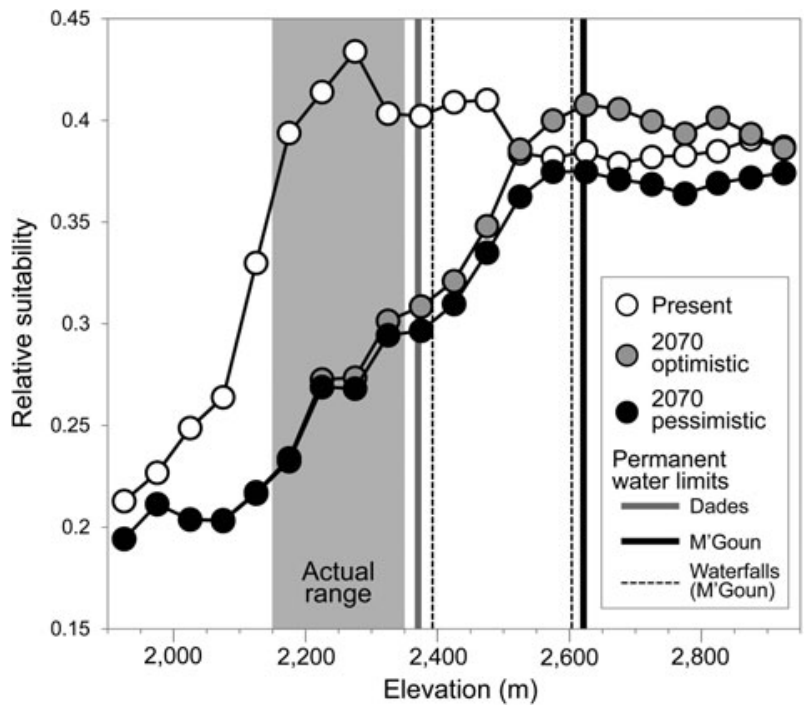

FIG. 4 Estimated habitat suitability for the Dades trout in relation to elevation, for the present and forecast for 2070 under two climatic scenarios (optimistic and pessimistic). The grey area represents the altitudinal range currently occupied by the species. Vertical lines denote barriers to movement along river corridors caused by the disappearance of permanent waters (solid lines) or waterfalls (broken lines).

riverine trout populations in northern Africa, occupying headwaters of all the main Moroccan watercourses, are not included in any of those five taxa and consequently their conservation status has not been assessed. There is an evident need to reach scientific consensus on the taxonomy of the brown trout complex to facilitate appropriate prioritization of conservation efforts. As exemplified by the critical status of the Dades trout, we suggest this need is urgent.

The conservation value of the Dades trout also relies on the biogeographical uniqueness of the Draa basin. The historical environmental dynamism of the Sahara Desert has blurred the limit between the Palearctic and Afrotropical biogeographical realms in northern Africa (Brito et al., 2014), and the Draa basin is probably the clearest extant example of that admixture of biotas. Apart from the Dades trout, the Draa river system hosts one fish species of Mediterranean affinities (Luciobarbus lepineyi) and, at low elevations, two Afrotropical relict cichlids (Oreochromis aureus and Coptodon zillii) (Clavero et al., 2015). While the Dades trout coexists with cold-dwelling aquatic taxa, such as the white-throated dipper Cinclus cinclus, in the headwaters, the lower reaches of the Draa river are inhabited by Egyptian cobras Naja haje and honey badgers Mellivora capensis, and held Nile crocodile Crocodylus niloticus populations until the beginning of the 2oth century (Brito et al., 2011b). Preserving and recovering the biogeographical mosaic of the Draa basin, of which the Dades trout is an irreplaceable piece, should be an international conservation priority. 


\section{Options for conserving the Dades trout}

The small stream stretches that constitute the entire habitat of the Dades trout are affected by erosion in their respective drainage areas. Erosion has long been a feature in the High Atlas Mountains (Bouzekraoui et al., 2016), where dragged sediments end up in water courses, leading to increased turbidity and substrate embeddedness. These conditions negatively affect a variety of stream trout species worldwide (Suttle et al., 2004; Harvey et al., 2009). Erosion is an especially pervasive threat for the Dades trout population in the M'Goun catchment (Fig. 3 d), where it decreases the quality of potentially suitable habitat. The Dades trout would benefit from the restoration of the M'Goun headwaters, which should focus simultaneously on the river bed (Sternecker et al., 2013) and on the whole drainage area (Walling \& Collins, 2008). Addressing erosion issues would require the involvement of the local population in the recovery of the hillslope vegetation cover. This is a challenging task because of the existence of complex traditional systems for the management of common resources, including wood and livestock areas, among Berber societies of the High Atlas (Hammi et al., 2010). Nevertheless, such an integrated restoration project could improve the conservation outlook for the Dades trout and serve as an example for similar interventions across the mountain ranges of northern Africa.

Doadrio et al. (2015) suggested that overfishing could be problematic for the Dades trout. Although we observed occasional trout fishing by local people, our impression is that these activities do not represent a serious threat; however, the impacts of fishing should be investigated (Lewin et al., 2006). Probably the most severe risk related to fishing activities would be the introduction of different brown trout lineages or the rainbow trout Oncorhynchus mykiss within the range of the Dades trout. Moroccan authorities have stocked trout in several watercourses across the country. The remoteness of the Dades trout range has probably prevented stocking operations but this could change in the near future with the improvement of local transport infrastructures and increasing tourism.

Because of the forecast decrease in the suitability of the current range of the Dades trout and the lack of permanent upstream aquatic environments, conservation action should involve adaptation measures to improve in situ resilience to climate change. Efforts should concentrate on the mitigation of temperature increases at the local scale (Orr et al., 2015), which would arguably be possible by enhancing the shading effects of riparian vegetation (Bowler et al., 2012). Riparian shade favours the viability of trout populations by potentially preventing the surpassing of lethal or sublethal water temperature thresholds (Broadmeadow et al., 2011). This buffering role would be critical for populations living at the extreme of their physiological temperature tolerances, such as both remaining Dades trout populations.
As in the case of the recovery of the vegetation in the drainage areas, enhancing vegetation in riparian areas would require the involvement of the local communities that exploit them.

There is an urgent need to start a captive breeding programme to maintain ex situ stocks of the Dades trout that would serve as insurance in the face of catastrophic events and future population declines as a result of climate change (Pritchard et al., 2012). Captive breeding has been widely developed in salmonids in general and brown trout in particular, but it has been aimed mainly at provisioning stocking operations to support sport fishing (e.g. Sanz et al., 2006). This was the main aim of the Moroccan programme for brown trout breeding conducted by the National Centre of Hydrobiology and Aquaculture, located in Azrou in the Middle Atlas. The Centre's experience and infrastructure would be ideal for attempting captive breeding of the Dades trout. An eventual ex situ conservation programme should conserve the genetic identity of the two populations.

\section{Conclusion}

The Dades trout is a Critically Endangered, restricted-range stream salmonid that is threatened by the loss of suitable habitat in its high-altitude environment as a result of climate change. The genetic and biogeographical singularity of the Dades trout should make it a conservation priority, but its survival, even in the short term, seems to be dependent on active management of the two remaining populations. Based on our knowledge of the whole distribution range of the species we propose specific and complementary management actions. The socio-economic context in the range of the Dades trout is challenging, as traditional Berber societies have complex rule systems for the exploitation of natural resources, but nevertheless the involvement of these societies will be vital in any conservation project for the Dades trout. Any such projects should be supported by participatory processes driven by effective mediation. Options to conserve the Dades trout are currently available but could disappear if work is not initiated in the near future.

\section{Acknowledgements}

We acknowledge the help, support and advice of Brahim Bizzi and his family at Kasbah Les Amis (M'semrir). Permissions were obtained from the Haut Commissariat aux Eaux et Forêts et à la Lutte Contre la Désertification $\mathrm{du}$ Royaume du Maroc. Funding was received from Estación Biológica de Doñana - Consejo Superior de Investigaciones Científicas (EBD-CSIC) through a microproject within the Spanish Severo Ochoa Programme (SEV-2012-0262), and from the National Geographic Society's Committee for Research and Exploration 
(\#9188-12). VH has a Ramón y Cajal contract funded by the Spanish Ministry of Science and Innovation and AV is funded by Fundação para a Ciência e Tecnologia (SFRH/ $\mathrm{BPD} / 77487 / 2011)$.

\section{Author contributions}

$\mathrm{MC}$ conceived the research and led the writing of the article, aided by all other authors. MC, JE and JC conducted the fieldwork. $\mathrm{VH}$ and $\mathrm{AV}$ performed most of the statistical analyses.

\section{References}

Azeroual, A. (2003) Monographie des poissons des eaux continentales du Maroc: systématique, distribution et écologie. $\mathrm{PhD}$ thesis. Université Mohammed V-Agdal, Rabat, Morocco.

Babault, J., Van den Driessche, J. \& Teixell, A. (2012) Longitudinal to transverse drainage network evolution in the High Atlas (Morocco): the role of tectonics. Tectonics, 31, TC4020.

Bernatchez, L. (2001) The evolutionary history of brown trout (Salmo trutta L.) inferred from phylogeographic, nested clade, and mismatch analyses of mitochondrial DNA variation. Evolution, 55, 351-379.

Bouzekraoui, H., El Khalki, Y., Mouaddine, A., Lhissou, R., El Youssi, M. \& BARAKAT, A. (2016) Characterization and dynamics of agroforestry landscape using geospatial techniques and field survey: a case study in central High-Atlas (Morocco). Agroforestry Systems, 90, 965-978.

Bowler, D.E., Mant, R., Orr, H., Hannah, D.M. \& Pullin, A.S. (2012) What are the effects of wooded riparian zones on stream temperature? Environmental Evidence, 1, 3.

Brito, J.C., Fahd, S., Martínez-Freiría, F., Tarroso, P., Larbes, S., Pleguezuelos, J.M. \& Santos, X. (2011a) Climate change and peripheral populations: predictions for a relict Mediterranean viper. Acta Herpetologica, 6, 105-118.

Brito, J.C., Godinho, R., Martínez-Freiría, F., Pleguezuelos, J.M., Rebelo, H., Santos, X. et al. (2014) Unravelling biodiversity, evolution and threats to conservation in the Sahara-Sahel. Biological Reviews, 89, 215-231.

Brito, J.C., Martínez-Freiría, F., Sierra, P., Sillero, N. \& Tarroso, P. (2011b) Crocodiles in the Sahara desert: an update of distribution, habitats and population status for conservation planning in Mauritania. PLoS ONE, 6(2), e14734.

Broadmeadow, S.B., Jones, J.G., Langford, T.E.L., Shaw, P.J. \& Nisbet, T.R. (2011) The influence of riparian shade on lowland stream water temperatures in southern England and their viability for brown trout. River Research and Applications, 27, 226-237.

Clavero, M., Esquivias, J., Qninba, A., Riesco, M., Calzada, J., Ribeiro, F. et al. (2015) Fish invading deserts: non-native species in arid Moroccan rivers. Aquatic Conservation: Marine and Freshwater Ecosystems, 25, 49-60.

Cortey, M., Vera, M., Pla, C. \& García-Marín, J.L. (2009) Northern and Southern expansions of Atlantic brown trout (Salmo trutta) populations during the Pleistocene. Biological Journal of the Linnean Society, 97, 904-917.

D’Amen, M., Zimmermann, N.E. \& Pearman, P.B. (2013) Conservation of phylogeographic lineages under climate change. Global Ecology and Biogeography, 22, 93-104.
Doadrio, I., Perea, S. \& Yahyaoui, A. (2015) Two new species of Atlantic trout (Actinopterygii, Salmonidae) from Morocco. Graellsia, 71, eо31.

Drake, N.A., Blench, R.M., Armitage, S.J., Bristow, C.S. \& White, K.H. (2011) Ancient watercourses and biogeography of the Sahara explain the peopling of the desert. Proceedings of the National Academy of Sciences of the United States of America, 108, 458-462.

Hammi, S., Simonneaux, V., Cordier, J.B., Genin, D., Alifriqui, M., Montes, N. \& Auclair, L. (2010) Can traditional forest management buffer forest depletion? Dynamics of Moroccan High Atlas Mountain forests using remote sensing and vegetation analysis. Forest Ecology and Management, 260, 1861-1872.

Harvey, B.C., White, J.L. \& Nakamoto, R.J. (2009) The effect of deposited fine sediment on summer survival and growth of rainbow trout in riffles of a small stream. North American Journal of Fisheries Management, 29, 434-440.

Hijmans, R.J., Cameron, S.E. \& Parra, J.L. (2014) WorldClim v. 1.4 Museum of Vertebrate Zoology, University of California, Berkeley. Http://www.worldclim.org/.

IUCN (2012) IUCN Red List Categories and Criteria. Version 3.1. 2nd edition. IUCN, Gland, Switzerland, and Cambridge, UK.

IUCN (2016) The IUCN Red List of Threatened Species 2016. Http:// www.iucnredlist.org [accessed 15 June 2016].

IUCN Standards and Petitions Subcommittee (2016) Guidelines for Using the IUCN Red List Categories and Criteria. Version 12. Http://www.iucnredlist.org/documents/RedList Guidelines.pdf [accessed January 2017].

Jonsson, B. \& Jonsson, N. (2011) Ecology of Atlantic Salmon and Brown Trout. Springer, Berlin, Germany.

Joppa, L.N., Butchart, S.H.M., Hoffmann, M., Bachman, S.P., АкÇАKАY A, H.R., Молт, J.F. et al. (2016). Impact of alternative metrics on estimates of extent of occurrence for extinction risk assessment. Conservation Biology, 30, 362-370.

Keith, P. \& Marion, L. (2002) Methodology for drawing up a Red List of threatened freshwater fish in France. Aquatic Conservation: Marine and Freshwater Ecosystems, 12, 169-179.

Körner, C. \& Spehn, E.M. (eds) (2002) Mountain Biodiversity: A Global Assessment. The Parthenon Publishing Group, London, UK.

Kottelat, M. \& Freyhof, J. (2007) Handbook of European Freshwater Fishes. Kottelat, Cornol and Freyhof, Berlin, Germany.

La Sorte, F.A. \& Jetz, W. (2010) Projected range contractions of montane biodiversity under global warming. Proceedings of the Royal Society B, http://dx.doi.org/10.1098/rspb.2010.0612.

Lesica, P. \& AlLEND ORF, F.W. (1995) When are peripheral populations valuable for conservation? Conservation Biology, 9, 753-760.

Lewin, W.C., Arlinghaus, R. \& Mehner, T. (2006) Documented and potential biological impacts of recreational fishing: insights for management and conservation. Reviews in Fisheries Science, 14, 305-367.

Mace, G.M., Collar, N.J., Gaston, K.J., Hilton-Taylor, C., AKÇAKaya, H.R., LeAder-Williams, N. et al. (2008) Quantification of extinction risk: IUCN's system for classifying threatened species. Conservation Biology, 22, 1424-1442.

Maceda-Veiga, A., Green, A.J. \& De Sostoa, A. (2014) Scaled body-mass index shows how habitat quality influences the condition of four fish taxa in north-eastern Spain and provides a novel indicator of ecosystem health. Freshwater Biology, 59, 1145-116o.

Nogués-Bravo, D., Araújo, M.B., Errea, M.P. \& Martinez-Rica, J.P. (2007) Exposure of global mountain systems to climate warming during the 21st century. Global Environmental Change, 17, 420-428.

OrR, H.G., Johnson, M.F., Wilby, R.L., Hatton-Ellis, T. \& BROADMEADOW, S. (2015) What else do managers need to know about warming rivers? A United Kingdom perspective. Wiley Interdisciplinary Reviews: Water, 2, 55-64. 
Pauli, H., Gottfried, M., Dullinger, S., Abdaladze, O., Akhalkatsi, M., Alonso, J.L.B. et al. (2012) Recent plant diversity changes on Europe's mountain summits. Science, 336, 353-355.

Pritchard, D.J., Fa, J.E., Oldfield, S. \& Harrop, S.R. (2012) Bring the captive closer to the wild: redefining the role of ex situ conservation. Oryx, 46, 18-23.

Pustovrh, G., Snoj, A. \& Bajec, S.S. (2014) Molecular phylogeny of Salmo of the western Balkans, based upon multiple nuclear loci. Genetics Selection Evolution, 46, 7.

Sanz, N., Cortey, M., Pla, C. \& García-Marín, J.L. (2006) Hatchery introgression blurs ancient hybridization between brown trout (Salmo trutta) lineages as indicated by complementary allozymes and mtDNA markers. Biological Conservation, 130, 278-289.

Schulz, O. \& Judex, M. (2008) IMPETUS Atlas Morocco. Research Results 2000-2007. 3rd edition. Department of Geography, University of Bonn, Bonn, Germany.

Simaika, J.P. \& Samways, M.J. (2010) Large-scale estimators of threatened freshwater catchment species relative to practical conservation management. Biological Conservation, 143, 311-320.

Snoj, A., Marić, S., Bajec, S.S., Berrebi, P., Janjani, S. \& Schöffmann, J. (2011) Phylogeographic structure and demographic patterns of brown trout in North-West Africa. Molecular Phylogenetics and Evolution, 61, 203-211.

Sternecker, K., Wild, R. \& Geist, J. (2013) Effects of substratum restoration on salmonid habitat quality in a subalpine stream. Environmental Biology of Fishes, 96, 1341-1351.
Suttle, K.B., Power, M.E., Levine, J.M. \& McNeely, C. (2004) How fine sediment in riverbeds impairs growth and survival of juvenile salmonids. Ecological Applications, 14, 969-974.

Verreycken, H., Belpaire, C., Van Thuyne, G., Breine, J., Buysse, D., Coeck, J. et al. (2014) IUCN Red List of freshwater fishes and lampreys in Flanders (north Belgium). Fisheries Management and Ecology, 21, 122-132.

WAlling, D.E. \& Collins, A.L. (2008) The catchment sediment budget as a management tool. Environmental Science \& Policy, 11, 136-143.

\section{Biographical sketches}

Miguel Clavero is a freshwater ecologist with interests in conservation, biological invasions and historical ecology. JAVIER CALZADA is a conservation biologist, mainly focused on mammals. JAVIER Esquivias is a biologist and documentary film-maker. ANA Veríssimo studies evolutionary processes driving biodiversity patterns, mainly in elasmobranchs. Virgilio Hermoso is interested in the application of systematic methods to address conservation and rehabilitation. AвDELJEввAR QNiNBa is a wildlife biologist interested in the ecology and conservation of arid and semi-arid systems. MI G U E L Delibes is a conservation ecologist who has studied a diverse array of organisms worldwide but with a special attachment to Doñana National Park, in south-west Spain. 